\title{
Mapping of the Invasive Species Hakea sericea Using Unmanned Aerial Vehicle (UAV) and WorldView-2 Imagery and an Object-Oriented Approach
}

\author{
Flor Alvarez-Taboada ${ }^{1, *}$ (D) , Claudio Paredes $^{2}$ and Julia Julián-Pelaz ${ }^{1}$ \\ 1 GEOINCA-202, Universidad de León, Campus de Ponferrada C/Avda. de Astorga s/n, 24401 Ponferrada, \\ León, Spain; jjulip00@estudiantes.unileon.es \\ 2 Escola Superior Agraria, Instituto Politécnico de Viana do Castelo, 4990-706 Refóios do Lima, Ponte de Lima, \\ Portugal; cparedes@esa.ipvc.pt \\ * Correspondence: flor.alvarez@unileon.es; Tel.: +34-987-442042
}

Academic Editors: Duccio Rocchini, Alfredo R. Huete and Prasad S. Thenkabail Received: 17 July 2017; Accepted: 30 August 2017; Published: 1 September 2017

\begin{abstract}
Invasive plants are non-native species that establish and spread in their new location, generating a negative impact on the local ecosystem and representing one of the most important causes of the extinction of local species. The first step for the control of invasion should be directed at understanding and quantification of their location, extent and evolution, namely the monitoring of the phenomenon. In this sense, the techniques and methods of remote sensing can be very useful. The aim of this paper was to identify and quantify the areas covered by the invasive plant Hakea sericea using high spatial resolution images obtained from aerial platforms (Unmanned Aerial Vehicle: UAV/drone) and orbital platforms (WorldView-2: WV2), following an object-oriented image analysis approach. The results showed that both data were suitable. WV2reached user and producer accuracies greater than 93\% (Estimate of Kappa (KHAT): 0.95), while the classifications with the UAV orthophotographs obtained accuracies higher than 75\% (KHAT: 0.51). The most suitable data to use as input consisted of using all of the multispectral bands that were available for each image. The addition of textural features did not increase the accuracies for the Hakea sericea class, but it did for the general classification using WV2.
\end{abstract}

Keywords: high spatial resolution; pan-sharpening; texture; OBIA; invasive plant

\section{Introduction}

Invasive alien plants are non-native species which become established and disperse in their new location, generating a negative impact on ecosystem services, economy and social welfare, and representing the second most significant cause of species extinction [1]. In the case of alien trees and shrubs, they often form dense stands which reduce surface water resources, diminish biological diversity and increase fire hazards [2].

In Europe, more than 12,000 alien species are listed, from which 10 to $15 \%$ are predicted to be invasive, with an estimated cost of 12 billion euros per year [3]. These numbers have led the European Parliament to adopt new legislation to prevent and manage this threat. In Portugal, more than 600 exotic species have been catalogued, which corresponds to ca. $18 \%$ of the total Continental Portuguese flora [4]. Eight per cent of those exotic species are considered to be invasive and they threaten the native flora and biodiversity [5]. Portuguese legislation [6] acknowledges 29 plan species as invasive, while some authors have already raised that number to 49 [7], highlighting that 66 more alien plant species are potentially invasive risks. In this context, assessing the size and location of 
the populations of these species is crucial to prevent their spread into new environments and also for setting management priorities for invasive plants [1,8-10].

This situation is aggravated in habitats and ecosystems which are particularly vulnerable [11] and prone to periodic wildfires [12], like the North of Portugal, where the National Park of Peneda-Gerês is located. Hakea sericea (Schrad and Wendl) is an invasive shrub which is colonizing large areas in the North of Portugal [1], and has been added to the list of invasive alien plants that was developed by the European and Mediterranean Plant Protection Organization (EPPO) in 2012. The distribution of this species is spatially irregular, since the seeds are largely dispersed by wind, creating new outbreaks which are usually located in disturbed areas and/or with low soil nutrients [1,2]. Where it invades, Hakea sericea forms dense impenetrable stands [13] and causes several negative impacts, including the reduction in indigenous species diversity [1] and increases in biomass, fuel loads and the intensity of wildfires [13]. Its quick spread in the North of Portugal has probably been caused by the large number of wildfires which have affected the area [14,15], since the seeds are only released when the plant dies or it is burnt $[2,8,11,16]$. Since the frequency and intensity of the fires in Portugal is growing [17], the risk of Hakea sericea spreading is growing too. In order to mitigate its effects and expansion, it is crucial to know the geographical location, extension and evolution of this species $[10,18]$. The tasks related to locating the populations of invasive plant species in space and time can be overcome with the use of different remote sensing sources and techniques, as stated by Bradley [12] and Huang and Asner [19] in two comprehensive reviews.

Although the identification and mapping of land cover are typical tasks in remote sensing, specific works about mapping invasive plant species were not common until the mid-1990s [19]. Since then, the resulting distribution maps have been used to target the management of early infestations [19,20], find the optimal time periods to apply the mitigation treatments [21], model the future invasion risk $[12,19,22]$ or monitor the effectiveness of the management actions [23]. Most works use just spectral information from the sensors to identify the invasive plants [20-29], although some studies have found that differences in texture and phenology are also effective for their detection $[12,19,27,30]$, as well as the fusion with non-optical data, like LiDAR (Light Detection And Ranging) point clouds [19,26,31].

Moderate spatial resolution imagery (pixel size larger than $10 \mathrm{~m}$ ) has been widely used to detect and monitor invasive plants; however, it is only effective when the patches and stands are large [21] and it is usually unsatisfactory for detecting alien plants in the ecotone or for detailed mapping in a small area [22,30,32-34]. In most cases, obtaining successful results with moderate spatial resolution datasets requires the data from the sensors pushing the limits of the temporal or the spectral resolution $[28,35,36]$, in order to find a unique feature which helps differentiate the invasive species [30].

Approaches using moderate spatial resolution imagery can be a more appropriate solution for large areas and for management at a large scale [30], while high-spatial resolution imagery (pixel size smaller than $10 \mathrm{~m}$ ) is necessary for a local or fine scale to provide more detailed information $[19,23,24,27,30]$ critical for targeted monitoring and eradication control. In some cases, the increased spectral or temporal resolution compensates for the low spatial resolution [19,37], as when comparing Pleiades versus Sentinel-2 imagery to detect two alien plant species in Kenya [24]. Bradley [12], Huang and Asner [19] and Müllerová et al. [30] have summarized the advantages and constraints of different types of remote sensing imagery in invasive species monitoring, and show that the choice of the most suitable imagery is case-specific, depending largely on both the target plant and the management goal to be achieved. Regarding Hakea sericea, Ounuan [29] used IKONOS and SPOT (Satellites Pour l'Observation de la Terre) imagery to map the bush in Portugal; the most accurate results (Estimate of Kappa (KHAT): 0.32) were achieved with IKONOS imagery.

Although high spatial resolution remote sensing has been proven to be a valid method to map these plants, there are still several drawbacks to these approaches, such as acquiring the data in a timely manner and at an affordable cost (from airborne or satellite sensors) $[19,27,37]$ or pre-processing the images (Unmanned Aerial Vehicle (UAV) data) [30]. Another issue to consider is the classification approach to apply. The traditional classification techniques that are based on pixels involve numerous 
constraints when they are applied to very high spatial resolution imagery (e.g., salt and pepper effect, noise due to small shadows) [38,39]. Some of those limitations can be overcome by an object oriented image analysis (OBIA), which defines a segment (also called object) as the minimum processing unit. A comprehensive review of the fundamentals of OBIA and its applications can be read in Blaschke [40]. In this context, Fernandez-Luque et al. [41] and Fernandez-Luque et al. [42] found that OBIA was suitable to map pervious and impervious areas using very high spatial resolution imagery (Archival orthophotographs, GeoEye-1, WorldView-2 (WV2)). Regarding alien invasive species, [23,24,30] found the object based approach successfully monitored and detected invasive grasses and trees in different environments using multiple high spatial resolution imagery, while Boelman [30] concluded that the choice between an object oriented or a pixel based approach depended on the plant monitored, the characteristics of the imagery (UAV versus Pleiades) and the time of acquisition.

Shamsoddini et al. [43] showed the importance of choosing a suitable feature space as input data and the relevance of using texture as a predictor when mapping vegetation using high spatial resolution imagery (WV2). Along the same lines, Bradley [12], Jones et al. [27] and Tsai and Chou [44] also found that the use of textural features improved the detection of invasive alien species, while West et al. [22] found vegetation indices useful to predict the distribution of Bromus tectorum (cheatgrass) in a post-wildfire landscape.

Since there is not a single straightforward approach which can be used to map most of the invasive shrubs, there is a research gap that needs to be filled in order to obtain an operational tool to detect and monitor the invasive species Hakea sericea using remote sensing techniques. Exploring the suitability of two different types of high spatial resolution imagery and the use of derived vegetation indices and textures to increase the accuracy of the results can help fill that gap. The working hypothesis is that if both sources of imagery are suitable, they can be used together to access different spatio-temporal scales of observation. The goal of this paper was to identify and quantify the areas covered by Hakea sericea in the study area, using high spatial resolution data from UAV and WV2, using an object oriented approach. The three objectives were: (i) to determine the suitability of WV2 and UAV imagery to map this species; (ii) to identify the optimal combination of bands, indices and textures; (iii) to assess if the accuracy of the classifications increases when textures are used.

\section{Study Area}

The study area was located in Viana de Castelo (the North of Portugal), in the "freguesías" (parishes) of Sopo, Covas, Villar de Mouros, Arga de Sao Joao and Arga de Baixo, which belong to the municipalities of Caminha and Vila Nova de Cerveira (Figure 1). The study area is comprised of several river basins, where the agricultural lands are located in the lowest parts of the valleys and account for $20 \%$ of the total area. Most of the land is covered by forests, shrubs or uncultivated fields. It was chosen due to the numerous areas that were colonized by Hakea sericea, and the ecological interest of Serra d'Arga (located in the study area), and which is aimed to be protected by Portuguese law due to its unique landscape. 


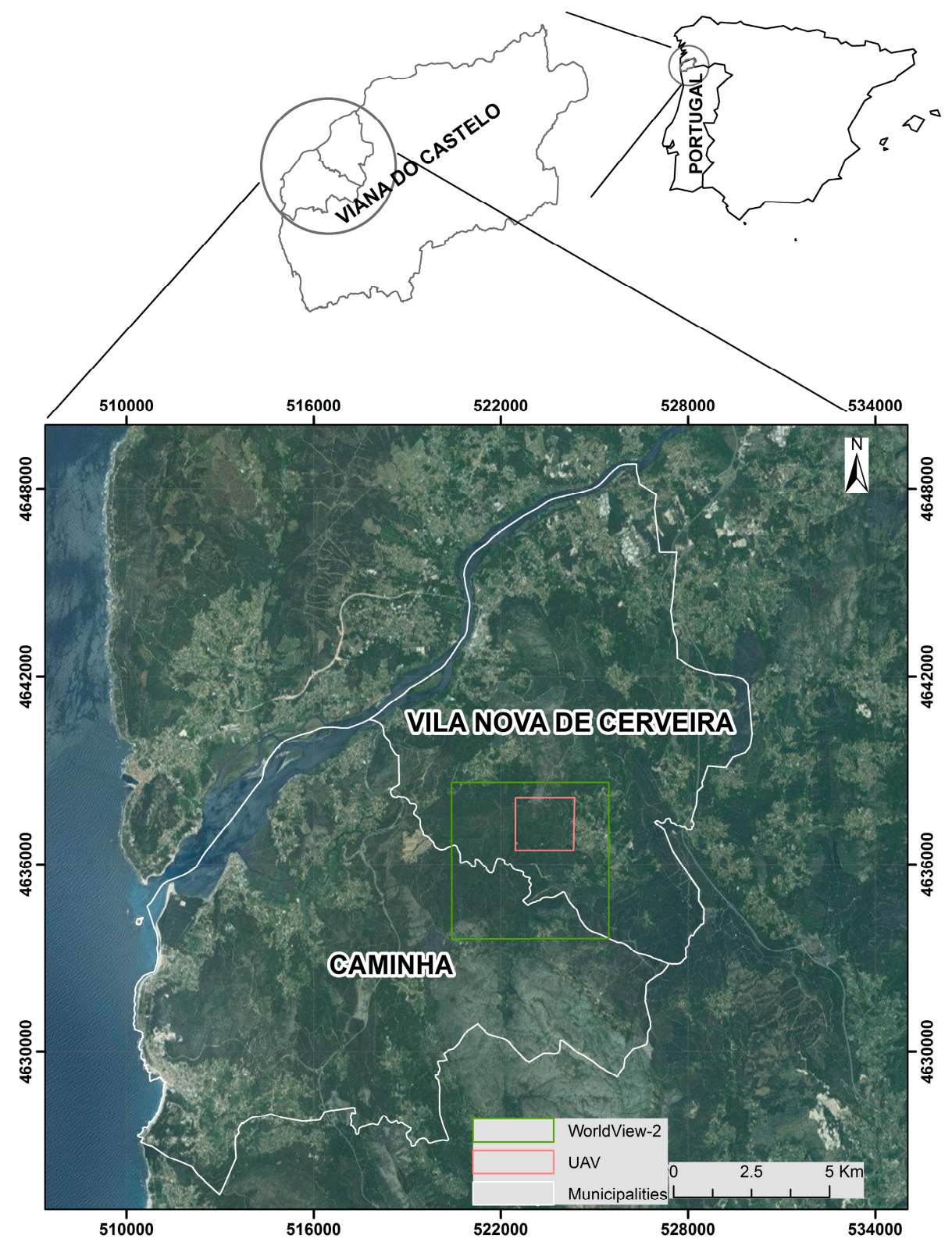

Figure 1. Study area located in Viana de Castelo (the North of Portugal), in the municipalities of Caminha and Vila Nova de Cerveira. Most of the land is covered by forests, shrubs or uncultivated fields. Coordinate reference system: WGS84 UTM29.

\section{Materials and Methods}

\subsection{Data}

The following imagery was used as spectral input data: (i) WV2 multispectral and panchromatic images gathered on 15 February 2012; (ii) R-G-B and NIR-R-B orthoimages obtained from two UAV flights carried out on 1 August 2013.

The WV2 images covered almost 2550 ha of the study area (Figure 1). The acquisition date was selected by taking into account the flowering period of Hakea sericea, which takes places in winter and precedes the flowering period of the other species located in the study area. Thus, the spectral signature of Hakea sericea would be easier to identify. The WV2 image was an Ortho-Ready Standard 2A product, geometrically corrected to WGS84 UTM Zone 29. The multispectral image consisted of 8 bands (coastal 
blue (CB), blue (B), green $(G)$, yellow $(Y)$, red $(R)$, red edge (RE), and two NIR (Nir1, Nir2)), with a spatial resolution (GSD) of $2 \mathrm{~m}$ and 16 bits of radiometric resolution. The panchromatic image (GSD: $0.5 \mathrm{~m}$ ) had the same radiometric resolution.

The UAV imagery was gathered during two flights carried out along the same flight line at noon on 1 August 2013. The drone Ebee ${ }^{\circledR}$ (https:/ / www.sensefly.com/fileadmin/user_upload/images / eBee-BROCHURE.pdf) carried the two cameras which were used during the flights. The visible data $(\mathrm{R}, \mathrm{G}, \mathrm{B})$ was gathered by a Canon IXUS $220 \mathrm{HS}$ and the R, G and Nir data were captured by a Canon PowerShot ELPH 300HS. The images from each flight were orthorectified to the WGS84 UTM Zone 29 coordinate system, using 50 ground control points and senseFly, with accuracies of $0.95 \mathrm{~m}$ for XY and $0.89 \mathrm{~m}$ for Z. As a result, a R-G-B and a Nir-R-B orthoimage with a GSD of $0.07 \mathrm{~m}$ and 8 bits of radiometric resolution were obtained. These orthoimages covered approximately 160 ha of the study area (Figure 1).

\subsection{Methods}

The workflow was structured in three main tasks (Figure 2): data pre-processing, classification and validation. Each process is described in the following sections.

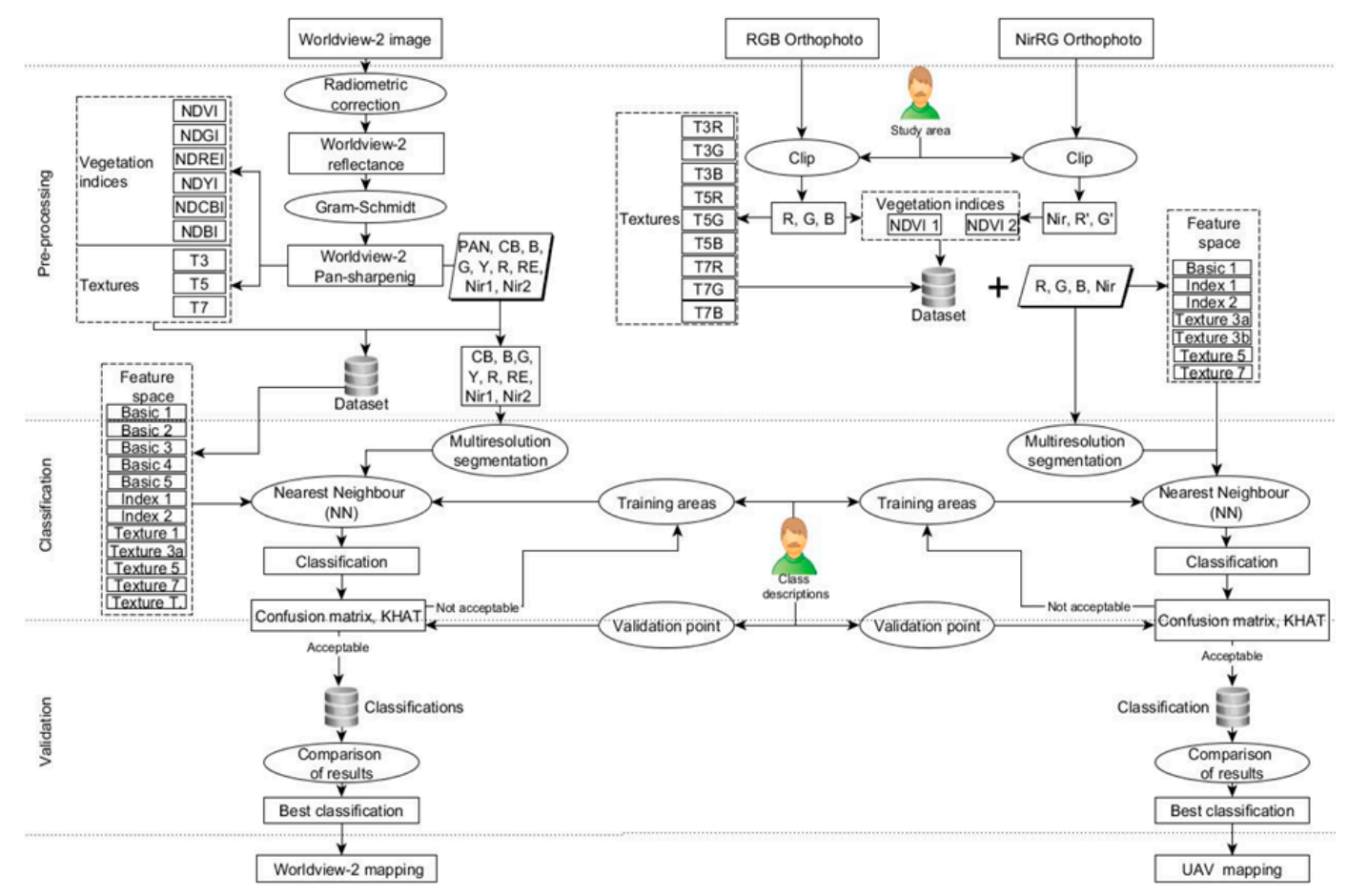

Figure 2. Summary of the workflow followed in this research. The processes are in circles, and the outputs in rectangles.

\subsubsection{Preprocessing}

The WV2 image was calibrated to at-sensor reflectance [45] and pan-sharpened using the panchromatic band. We used the Gram-Schmidt (GS) pan-sharpening approach [46] in order to make the spatial resolution of the WV2 and the UAV orthoimages more comparable. The spectral dimensionality of the WV2 data was increased by calculating vegetation indices and textural features. The following indices were computed: NDVI (Normalized Difference Vegetation Index), NDGI (Normalized Difference Green Index), NDYI (Normalized Difference Yellow Index), NDREI (Normalized Difference Red Edge Index), NDCBI (Normalized Difference Coastal Blue Index) and NDBI (Normalized Difference Blue Index). Their equations are available in Jensen [47] 
and Fernandez-Luque et al. [41]. Regarding the textural features, we selected the local variance and the $3 \times 3,5 \times 5$ and $7 \times 7$ pixel window sizes as texture indicators, due to their suitability to map land cover from WV2 images and orthoimages [42]. The three textural features were computed for the PAN (Panchromatic) image (T3, T5, T7), since it had the highest spatial resolution. Therefore, the final feature space for the WV2 image comprised of 18 bands: 8 multispectral bands, 1 PAN, 6 vegetation indices and 3 textural features (Figure 2).

The spectral dimensionality of the UAV orthoimages was also increased by calculating the vegetation indices and textural features. Two NDVIs were derived: (i) NDVI-1: using the red and Nir bands from the NirRG orthoimage; and (ii) NDVI-2: using the red band from the RGB orthoimage and the Nir band from the NirRG orthoimage. The textural features were computed following a similar procedure as the one that was used for WV2, so the local variance was calculated for each band of the RGB orthoimage using $3 \times 3,5 \times 5$ and $7 \times 7$ pixel window sizes [10] (T3R, T3G, T3B, T5R, T5G, T5B, T7R, T7G, T7B). As a result, the final feature space for the UAV orthoimages comprised of 15 bands: 4 multispectral bands (RRGB, GRGB, BRGB, NirNirRG), 2 vegetation indices and 9 textural features (Figure 2).

All of the tasks were completed using the software ENVI 5.0.

\subsubsection{Processing and Analysis (Classification)}

An object-based image analysis was carried out in order to identify seven different classes of land cover in the study area (Hakea sericea, Woodlands, Infrastructures, Bare soil, Shrubs, Agricultural lands and Water), using a supervised classification approach with the nearest neighbor algorithm (Figure 2). This approach requires creating objects from pixels, a process which is known as segmentation. We used the multiresolution segmentation algorithm implemented in eCognition 8.9 [48], which has been successfully applied to segment WV2 imagery and very high spatial resolution orthoimages [40-42]. The parameters which had to be defined in order to apply the algorithm were: the input data (layers), the scale parameter, and the homogeneity criteria. The characteristics of each parameter are described in Definiens Imaging [49]. The WV2 image was segmented using the 8 multispectral pan-sharpened bands as input data, with the R, G, RE, Nir1 and Nir2 bands having double the weight of the CB, B, and $Y$ bands. After several tests, a scale parameter of 20, a shape of 0.3 and a compactness of 0.5 were chosen, in order to obtain homogeneous objects which did not cover more than one class. Following a similar procedure, the UAV imagery was segmented using the 3 bands of the RGB image and the Nir band of the NirRG image as input data, with a scale parameter of 50 , a shape of 0.2 and compactness of 0.5 .

The training areas for each class were defined, taking into account the sample unit and the sample size. Table 1 shows the training areas for each land cover class. It should be noted that in the area covered by the UAV orthoimages, two of the land cover classes were missing (Water and Agricultural lands), so the training areas were not defined for those classes.

Table 1. Training areas and validation points for each land cover class.

\begin{tabular}{ccccc}
\hline \multirow{2}{*}{ Class } & \multicolumn{2}{c}{ WorldView-2 } & \multicolumn{2}{c}{ UAV } \\
\cline { 2 - 5 } & Training Areas & Validation Points & Training Areas & Validation Points \\
\hline Forest & 208 & 101 & 111 & 30 \\
Hakea sericea & 95 & 76 & 54 & 50 \\
Shrubs & 83 & 86 & 17 & 31 \\
Infrastructures & 288 & 43 & 12 & 47 \\
Bare soil & 98 & 51 & 32 & 54 \\
Agriculture & 98 & 46 & - & - \\
Water & 6 & 8 & - & - \\
Total & 876 & 411 & 226 & 212 \\
\hline
\end{tabular}


The next step consisted of defining the data (spectral bands, vegetation indices, textural features) that were used as input to classify the images. Thus, 12 feature spaces (FS) were defined for the VW2 classification and 8 FS for the orthoimages (Table 2), based on the results obtained by Fernandez-Luque et al. [42]. The FS that were tested were grouped as: (i) basic information (combinations of the available spectral bands for the WV2 and the UAV orthoimages); (ii) rates including vegetation indices; and (iii) several combinations of texture indices based on the local variance: Index 2 plus T3, T5 or T7 (obtaining Texture3, Texture5 and Texture7), Index2 plus all the different texture indices (obtaining TextureAll, for WV2), and Basic1 plus T3, T5, and T7 (in order to determine the influence of the Index 2 feature set).

Table 2. Set of spectral bands, indices and textures which define each feature space (FS). Notes: for Unmanned Aerial Vehicle (UAV) imagery, bands R, G, B belong to the RGB orthoimage and the Nir band to the NIrRG orthoimage.

\begin{tabular}{|c|c|c|}
\hline FS & UAV Orthoimages & WorldView-2 \\
\hline Basic 1 & $R+G+B+N i r$ & $R+G+B+N i r 1$ \\
\hline Basic 2 & - & $\mathrm{R}+\mathrm{G}+\mathrm{B}+\mathrm{Nir} 1+\mathrm{PAN}$ \\
\hline Basic 3 & - & $R+G+B+N i r 1+C B+Y+R E+N i r 2$ \\
\hline Basic 4 & - & Basic $3+$ PAN \\
\hline Basic 5 & - & Nir1 + Nir2 + RE + R \\
\hline Index 1 & Basic 1 + NDVI-1 & $\begin{array}{c}\text { NDVI + NDGI + NDYI + NDREI + } \\
\text { NDCBI + NDBI }\end{array}$ \\
\hline Index 2 & Basic $1+$ NDVI-2 & Basic $1+\operatorname{Index} 1$ \\
\hline Texture 1 & $\begin{array}{c}\text { Basic } 1+(\mathrm{T} 3 \mathrm{R}+\mathrm{T} 3 \mathrm{G}+\mathrm{T} 3 \mathrm{~B})+ \\
(\mathrm{T} 5 \mathrm{R}+\mathrm{T} 5 \mathrm{G}+\mathrm{T} 5 \mathrm{~B})+(\mathrm{T} 7 \mathrm{R}+\mathrm{T} 7 \mathrm{G}+\mathrm{T} 7 \mathrm{~B})\end{array}$ & Basic $3+$ T3PAN + T5PAN + T7PAN \\
\hline Texture 3a & Index $1+\mathrm{T} 3 \mathrm{R}+\mathrm{T} 3 \mathrm{G}+\mathrm{T} 3 \mathrm{~B}$ & Index $2+$ T3PAN \\
\hline Texture $3 b$ & Basic $1+T 3 R+T 3 G+T 3 B$ & - \\
\hline Texture 5 & Index $1+\mathrm{T} 5 \mathrm{R}+\mathrm{T} 5 \mathrm{G}+\mathrm{T} 5 \mathrm{~B}$ & Index $2+$ T5PAN \\
\hline Texture 7 & Index $1+\mathrm{T} 7 \mathrm{R}+\mathrm{T} 7 \mathrm{G}+\mathrm{T} 7 \mathrm{~B}$ & Index $2+$ T7PAN \\
\hline Texture A & - & Index $2+$ T3PAN + T5PAN + T7PAN \\
\hline
\end{tabular}

The classification algorithm that was applied was the Nearest Neighbor (NN) algorithm. This non-parametric method achieves suitable results when the number of required training samples is not very high [50]. The 1-NN approach [51], which is implemented in the eCognition software, was used. This approach computes the membership probability value of every object belonging to each class $[50,52]$. The values of the parameters slope and minimum distance to the samples (as defined by Baatz et al. [53]), were set to 0.2 and 0.7 , respectively.

\subsubsection{Validation}

In order to compare the results of the classifications using the different FS, defined in Table 2, the confusion matrix, overall accuracy (OA), user's accuracy (UA), producer's accuracy (PA) and an estimate of Kappa (KHAT) (one for the complete classification and another one for the Hakea sericea class) were calculated, as described in Congalton and Green [54]. The confidence intervals for the accuracies were calculated using the adjusted Wald method $(p<0.05)$, because it corresponds to the maximum likelihood estimate when the sample size is not large [55]. A random stratified sampling design was followed in order to choose the validation points: 411 for WV2 and 212 for the UAV orthoimagery. The validation points were verified in the field. The Hakea sericea class was validated using 76 and 50 validation points (for WV2 and UAV data, respectively), which is a suitable sample according to Congalton [56]. The number of validation points for each land cover class is displayed in Table 1.

To determine whether the classification was significantly better than a random classification, the $Z$ statistic for the global KHAT and the KHAT for the Hakea sericea class $(p<0.05)$ was calculated [54]. In addition, the test described in Fernandez-Luque et al. [41] and Congalton and Green [54] was applied, and the statistic $Z i j$ was calculated to determine whether the two KHAT (and therefore two confusion 
matrices) were statistically different $(p<0.05$ or $p<0.10$ ) [Equation (1)]. This test was used to make comparisons between the complete classifications (all the land cover classes) and also between the classifications if only the Hakea sericea class was considered. If $Z i j \geq 1.96$, the error matrices $i$ and $j$ are considered significantly different at a $95 \%$ confidence level. The threshold value for a $90 \%$ confidence level was 1.654. Then, 144 comparisons were made for the WV2, while the number of comparisons between the UAV classifications was 64 .

$$
Z_{i j}=\frac{\left|\widehat{K}_{i}-\widehat{K}_{j}\right|}{\sqrt{\widehat{\operatorname{var}}\left(\widehat{K}_{i}\right)+\widehat{\operatorname{var}}\left(\widehat{K}_{j}\right)}}
$$

where $\widehat{K}_{i}$ and $\widehat{K}_{j}$ represent KHAT (the estimate of kappa) for the confusion matrix $i$ and $j$, correspondingly; $\widehat{\operatorname{var}}\left(\widehat{K}_{i}\right)$ and $\widehat{\operatorname{var}}\left(\widehat{K}_{j}\right)$ are estimates of the variance of confusion matrix $i$ and $j$, correspondingly (see [21] for further information).

\subsubsection{Feature Space Selection}

The criteria to choose the most suitable FS for the mapping of Hakea sericea using WV2 imagery or UAV are listed below (in this order of priority). If two or more FS were not significantly different considering the first criterion, the second was tested, and if needed the following ones.

1. The highest KHAT for the Hakea sericea class (with a statistically significant difference; $p<0.05$ ).

2. The highest producer's accuracy the Hakea sericea class (lowest omission error). The classifications will be used to locate Hakea sericea with the aim of eliminating them; therefore it is more important to minimize the omission error than the commission error.

3. The highest user's accuracy for the Hakea sericea class (lowest commission error).

4. Minimum volume and complexity of the input data (i.e., feature space, need of derived data like indices), because of their contribution to the processing time.

5. The highest overall KHAT (with a statistically significant difference; $p<0.05$ ).

6. The highest overall accuracy of the classification.

\section{Results}

\subsection{WorldView-2}

The highest PA values for the Hakea sericea class (lowest omission errors) were obtained when using the feature spaces "Basic 3", "Basic 4" and "Texture 1" (93.59\%) (Table 3). This result shows that adding textural features did not diminish the omission error for this class. On the other hand, the PA value obtained with "Index 1" (the lowest value, 51.28\%) showed that the use of indices did not increase the accuracy for this class. The UA was higher than PA in all cases for the Hakea sericea class, so the commission errors were smaller than the omission errors. The highest UA was reached when using Basic 3; therefore the addition of textural features did not make the commission error of the class decrease. The lowest UA and PA were obtained using "Index 1" and "Basic 5".

As a measure of agreement or accuracy, KHAT is considered to show strong agreement when it is greater than 0.75 [57], while values lower than 0.40 indicate poor agreement [54]. All of the KHAT values for the Hakea sericea class were statistically significant at a $95 \%$ confidence level $(Z>1.96)$. The agreement for the Hakea sericea class was greater than $80 \%$ in all the classifications (i.e., KHAT > 0.80) (Table 3). The test to compare the accuracies (Zij) showed that all the FS were significantly more accurate than "Index 1 " $(p<0.10)$. There were no significant differences among the classifications involving textural features $(p<0.10)$. 
Table 3. General accuracy results for the WorldView-2 (WV2) study. Overall Accuracy (OA), Producer's Accuracy (PA), and User's Accuracy (UA) values are expressed in \%. The Wald adjusted confidence intervals $(p<0.05)$ are shown for PA and UA. Along the KHAT column, figures presenting different letters indicate significant differences for the KHAT statistic $(p<0.05)$.

\begin{tabular}{cccccc}
\hline \multirow{2}{*}{ Feature Space } & \multicolumn{3}{c}{ All Classes } & \multicolumn{3}{c}{ Hakea sericea } \\
\cline { 2 - 6 } & OA (\%) & KHAT & PA (\%) & UA (\%) & KHAT \\
\hline Basic 1 (B1) & 75.61 & $0.70^{\mathrm{a}}$ & $76.92(66.97-85.63)$ & $89.55(80.96-96.03)$ & $0.88^{\mathrm{ab}}$ \\
Basic 2 (B2) & 79.02 & $0.74^{\text {ab }}$ & $89.74(81.92-95.74)$ & $92.11(84.79-97.43)$ & $0.91^{\mathrm{ab}}$ \\
Basic 3 (B3) & 80.98 & $0.77^{\mathrm{b}}$ & $93.59(86.84-98.33)$ & $94.81(88.42-99.17)$ & $0.95^{\mathrm{b}}$ \\
Basic 4 (B4) & 81.22 & $0.77^{\mathrm{b}}$ & $93.59(86.84-98.33)$ & $93.59(86.84-98.33)$ & $0.93^{\mathrm{b}}$ \\
Basic 5 (B5) & 78.05 & $0.73^{\mathrm{ab}}$ & $89.74(78.05-93.17)$ & $88.61(80.58-94.88)$ & $0.87^{\mathrm{ab}}$ \\
Index 1 (I1) & 70.00 & $0.63^{\mathrm{c}}$ & $51.28(40.29-62.22)$ & $83.33(71.46-92.74)$ & $0.81^{\mathrm{a}}$ \\
Index 2 (I2) & 74.63 & $0.69^{\mathrm{c}}$ & $76.92(66.97-85.63)$ & $89.55(80.96-96.03)$ & $0.88^{\mathrm{ab}}$ \\
Texture1 (T1) & 82.20 & $0.78^{\mathrm{b}}$ & $93.59(86.84-98.33)$ & $93.59(86.84-98.33)$ & $0.93^{\mathrm{b}}$ \\
Texture3a (T3a) & 80.00 & $0.75^{\mathrm{ab}}$ & $88.46(80.34-94.81)$ & $93.24(86.16-98.23)$ & $0.93^{\mathrm{b}}$ \\
Texture5 (T5) & 80.00 & $0.75^{\mathrm{ab}}$ & $89.74(81.92-95.74)$ & $93.33(86.33-98.26)$ & $0.93^{\mathrm{b}}$ \\
Texture7 (T7) & 80.24 & $0.76^{\mathrm{ab}}$ & $91.03(83.52-96.64)$ & $93.42(86.50-98.28)$ & $0.93^{\mathrm{b}}$ \\
TextureAll (TA) & 81.46 & $0.77^{\mathrm{b}}$ & $91.03(83.52-96.64)$ & $94.67(88.12-99.07)$ & $0.94^{\mathrm{b}}$ \\
\hline
\end{tabular}

Overall, the KHAT showed that all the classifications had a moderate or strong agreement (between 0.63 and 0.77) (Table 3). All the error matrices (classifications) were statistically significant at a $95 \%$ confidence level, since $Z>1.96$. All the FS which included textures provided results that showed a strong agreement (KHAT $\geq 0.75)$. The overall KHAT values that were obtained in this work (excluding the results from using "Index 1" or "Index 2") were larger than the ones in Fernandez-Luque et al. [42], which were between 0.3841 and 0.7734 . The results of the Zij test to compare the overall KHAT showed that the classifications provided by "Basic 3" and "Basic 4" had a significantly higher agreement than "Basic 1 " ( $p<0,10$ and $p<0.05$, respectively); therefore, the addition of the $\mathrm{CB}, \mathrm{Y}, \mathrm{RE}$ and Nir2 bands as input data improved the classification. All the FS produced more accurate classifications than "Index 1" ( $p<0.10$ for "Basic 1 " and $p<0.05$ for the other FS). There were no significant differences among the classifications using textural features $(p<0.10)$ or indices $(p<0.10)$. Therefore, the most accurate classifications according to the overall KHAT were the ones using the following feature spaces: "Basic 2", “Basic 3", "Basic 4", “Texture 1", “Texture 3a", "Texture $3 b$ ", "Texture 5 " and "Texture 7 ", since there were no significant differences among them and they showed the highest KHAT values.

\section{2. $U A V$}

The data set "Texture 1" (80.77\%) achieved the highest PA for the Hakea sericea class (lowest omission error), followed by "Basic 1", "Index 1", and "Index 2" (76.92\%) (Table 4). The lowest PA was obtained when using "Texture 5" (71.15\%). This result showed that, when textural features with an unsuitable window size (in this case, equal to or greater than 5 pixels) were included, the omission error for the target class increased. Regarding the UA, it was lower than the PA in all cases, so the commission errors were larger than the omission errors (opposite of the WV2 classifications). The highest UA was obtained by the datasets "Basic 1" and "Index 2". The latter showed that when the NDVI was included as input data, it did not diminish the commission error for this class. The highest omission errors were achieved by the datasets which contain textural features, in particular "Texture 7". 
Table 4. General accuracy results for the UAV orthoimage study. OA, PA, and UA values are expressed in $\%$. The Wald adjusted confidence intervals $(p<0.05)$ are shown for PA and UA. Along the KHAT column, figures presenting different letters indicate significant differences for the KHAT statistic $(p<0.05)$.

\begin{tabular}{cccccc}
\hline \multirow{2}{*}{ Feature Space } & \multicolumn{2}{c}{ All Classes } & \multicolumn{3}{c}{ Hakea sericea } \\
\cline { 2 - 6 } & OA (\%) & KHAT & PA (\%) & UA (\%) & KHAT \\
\hline Basic 1 (B1) & 75.47 & $0.68^{\mathrm{a}}$ & $76.92(64.59-87.41)$ & $72.90(60.44-83.87)$ & 0.51 \\
Index 1 (I1) & 75.00 & $0.68^{\mathrm{a}}$ & $76.92(64.59-87.41)$ & $72.90(60.44-83.87)$ & 0.51 \\
Index 2 (I2) & 75.47 & $0.68^{\mathrm{a}}$ & $76.92(64.59-87.41)$ & $72.90(60.44-83.87)$ & 0.51 \\
Texture1 (T1) & 66.98 & $0.57^{\mathrm{bc}}$ & $80.77(68.98-90.46)$ & $66.94(55.44-77.75)$ & 0.43 \\
Texture3a (T3a) & 69.34 & $0.61^{\mathrm{b}}$ & $76.92(64.59-87.41)$ & $70.93(58.68-81.96)$ & 0.48 \\
Texture3b (T3b) & 69.81 & $0.61^{\mathrm{b}}$ & $76.92(64.59-87.41)$ & $70.93(58.68-81.96)$ & 0.48 \\
Texture5 (T5) & 67.45 & $0.58^{\mathrm{c}}$ & $71.15(58.24-82.62)$ & $67.14(54.85-78.61)$ & 0.43 \\
Texture7 (T7) & 65.57 & $0.56^{\mathrm{c}}$ & $73.08(60.33-84.24)$ & $71.66(59.00-82.93)$ & 0.49 \\
\hline
\end{tabular}

The KHAT for the Hakea sericea class ranged between 0.43 and 0.51 , which indicated a moderate agreement [54]. The test to compare the accuracies for the target class ( $\mathrm{Zij}$ ) showed that there were no significant differences among the classifications $(p<0.10)$, and therefore none of the classifications could be considered more accurate that the others.

The overall KHAT showed moderate agreement for all the classifications $(0.56 \leq$ KHAT $\leq 0.68)$. The classifications using the datasets "Basic 1", "Index 1" and "Index 2" achieved the highest agreement, since they provided the largest KHAT, and the $\mathrm{Zij}$ statistic indicated that there were no significant differences among them $(p<0.05)$. The classifications which did not use textural features were significantly more accurate than the ones using them $(p<0.05)$. Hence, using textural features did not improve the overall agreement of the classification.

\subsection{Feature Space Selection}

Taking into account the criteria described in Section 3.2.4, the most suitable data set to map Hakea sericea using the WV2 image was the dataset "Basic 3" (Table 5). This dataset led to an OA of $80.98 \%$ (KHAT: 0.77), and a UA and PA for Hakea sericea of $94.81 \%$ and $93.59 \%$, respectively (KHAT: 0.81). Although it was not required, the spatial representation of the classification was reviewed and considered satisfactory (Figure 3). Regarding the UAV orthoimages, the most accurate results were obtained using the "Basic 1" set (Red, Green, Blue, NIR), achieving an OA of 75.47\% (KHAT: 0.68), and UA and PA for Hakea sericea of $72.90 \%$ and $78.00 \%$, respectively (KHAT: 0.73 ) (Table 5). The spatial representation of the classification was reviewed and considered satisfactory (Figure 4).

Table 5. Characteristics of the selected feature spaces for classifying the WV2 image and the UAV orthoimages.

\begin{tabular}{ccc}
\hline Feature Space & WorldView-2 & UAV \\
\hline Name & Basic 3 & Basic 1 \\
KHAT (Hakea sericea) & 0.95 & 0.51 \\
Producer's accuracy (\%) & 93.59 & 76.92 \\
User's accuracy (\%) & 94.81 & 72.90 \\
Bands & $\mathrm{CB}, \mathrm{B}, \mathrm{G}, \mathrm{Y}, \mathrm{R}, \mathrm{RE}, \mathrm{Nir} 1, \mathrm{Nir} 2$ & $\mathrm{R}, \mathrm{G}, \mathrm{B}, \mathrm{Nir}$ \\
Overall accuracy (\%) & 80.98 & 75.47 \\
KHAT (global) & 0.77 & 0.68 \\
\hline
\end{tabular}




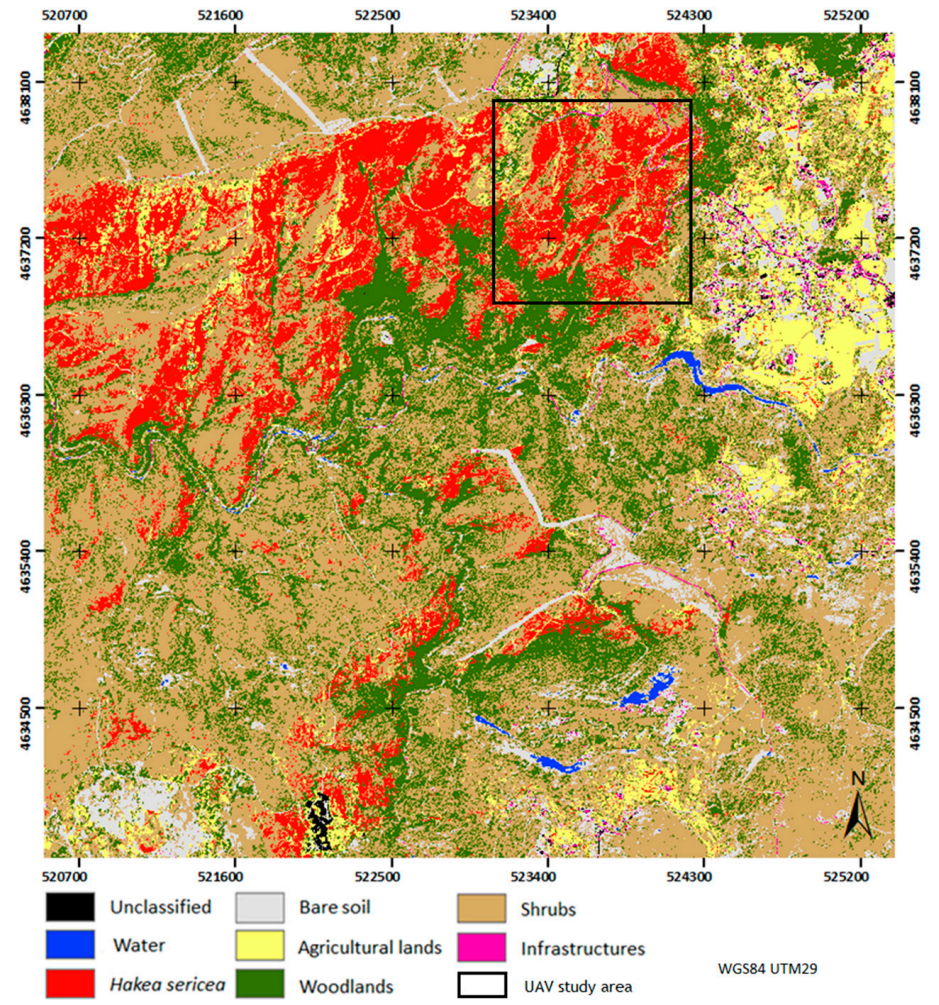

Figure 3. Map of land cover classes using WorldView-2 (WV2) (15 February 2012) and dataset "Basic 3". Note: Hakea sericea is mapped in red. The study area covered by the UAV imagery has been included for comparative purposes.

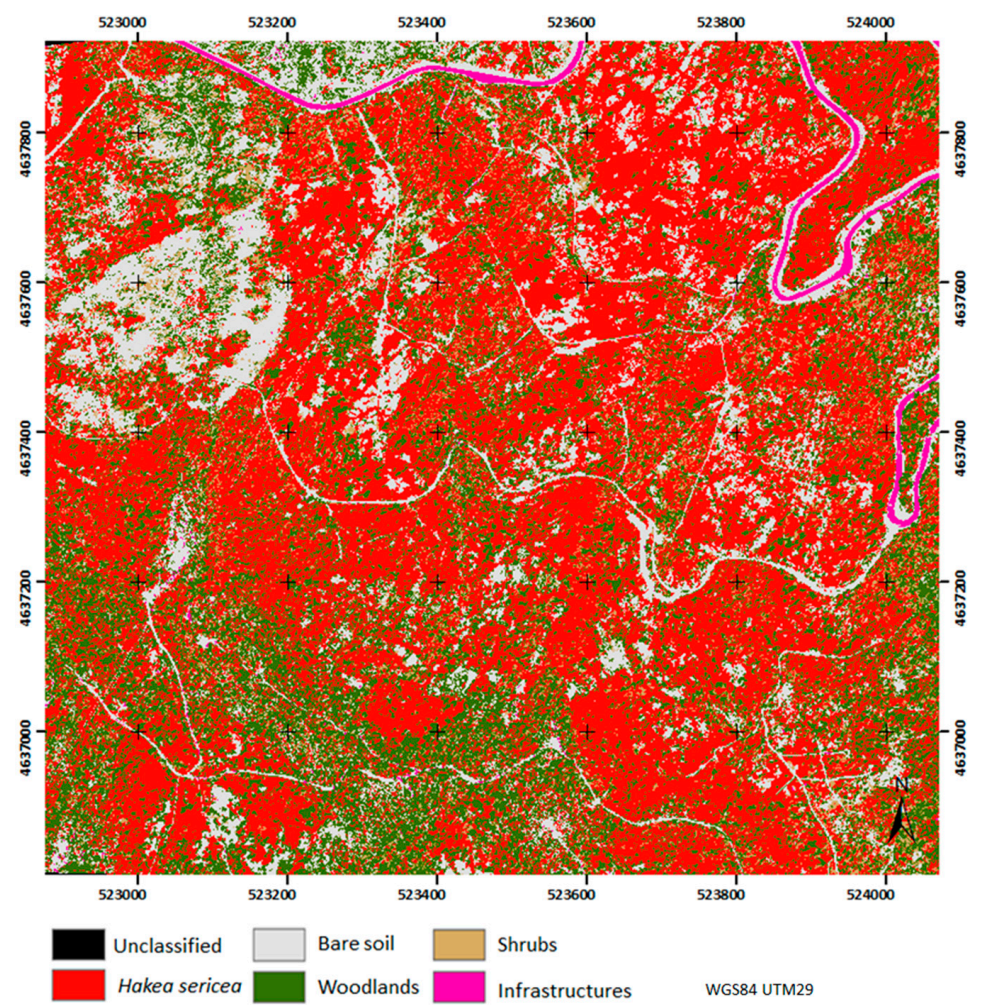

Figure 4. Map of land cover classes using UAV orthoimages (1 August 2013) and dataset "Basic 1". Note: Hakea sericea is mapped in red. 


\subsection{Area Colonized by the Hakea sericea in the Study Area}

The extension colonized by Hakea sericea in the study area covered by the WV2 image was approximately 279.216 ha, which represented $10.96 \%$ of the total area (Figure 3 ). Regarding the area studied using UAV imagery, the Hakea sericea occupied 63.48 ha ( $40.58 \%$ of the total extension) (Figure 4). It should be noted that the area covered by the different classes was not comparable between the classifications, since the study area was different for each case. Although the images were not captured on the same dates or during the same season, in the area where the images overlap, the difference in the extension provided by both sources of imagery was smaller than $15 \%$ (63.48 ha for the UAV and 55.16 ha for WV2).

\section{Discussion}

The WV2 and UAV (Red, Green, Blue, NIR) images produced accurate maps of the distribution of Hakea sericea in the study area, with omission and commission errors smaller than $10 \%$ and $30 \%$, respectively. The use of high spatial resolution data for detecting or monitoring alien invasive species has also provided successful results for other species, such as Spartina cordifolia by using Google Earth images [19], Squismus arabicus [58] and Melaleuca quinquenervia [37] with IKONOS imagery, Lythrum salicaria and others with Quickbird [59], Prosopis spp. with Pleiades and 10-m Sentinel-2 data [24], or Heracleum mantegazzianum and Fallopia japonica with Pleiades 1B and (Red, Green, Blue, NIR) UAV images [30].

The accuracies obtained with WV2 (PA: 93.59\%; UA: 94.81\%) are within the range or higher than the ones attained in the works mentioned above. Two factors may have played a significant role in these results: the spectral resolution and the date of acquisition. On the one hand, the low spatial resolution (compared to the UAV data, for instance) can be compensated by a more detailed spectral signature derived from more spectral bands [24], as shown by the errors achieved, which were smaller than the ones obtained with Pleiades [24,30] or UAV [30] for other species. On the other hand, the WV2 image was gathered in February, when the bush is in bloom, which provides a characteristic spectral signature which makes the detection easier, since most of the native plants are not yet in the flowering season. Unique phenological characteristics have been successfully used by other authors to monitor alien species, mainly during the flowering or fruiting season [12,30,60-62], demonstrating that regardless of the imagery or classification method, phenology is the key issue for the detection of many species $[12,19,63,64]$. Regarding the accuracies obtained with the UAV imagery (PA: 76.92\%; UA: $72.90 \%$ ), it should be pointed out that the areas with large and thick patches of Hakea sericea, where there were no trees, were classified more accurately than the areas where forest stands are present (SW of the UAV study area, Figure 4).

The mapping accuracies obtained by using WV2 or UAV imagery are sufficient for its operational implementation to create maps for locating and monitoring Hakea sericea in the North of Portugal. Both imagery sources can be used together to access different spatio-temporal scales of observation. There is a need for developing management strategies at different spatial scales $[10,18]$, since the detection at early stages, the detection of mature stands/patches or the monitoring of the control measures do not have the same requirements of spatial accuracy and detail. In the case of Hakea sericea, the detection should be done primarily at a regional scale (since the invasion covers large areas), while the estimation of the effectiveness of the control (more likely to be concentrated in small areas) requires a finer spatial and temporal assessment [8]. Therefore, we recommend the use of satellite imagery for works with a moderate spatial and temporal coverage, and UAV data for high spatial and temporal resolution outputs.

The use of spectral indices or textures did not increase the accuracy of the mapping of Hakea sericea using WV2 or UAV imagery, since the two most suitable datasets consisted of all the spectral bands available for the image. From the point of view of the processing time, these two datasets (Basic 3 and Basic 1) were some of the least complex datasets and therefore they could be used operationally. These results for WV2 contrast with Fernandez-Luque et al. [42], which found that the most suitable 
dataset to classify pervious and impervious areas using WV2 imagery included textural features. It should be highlighted that that work did not distinguish between vegetation land covers. Moreover, the fact that the species was in bloom made its spectral signature easier to differentiate, and therefore the margin for achieving significantly more accurate results was probably smaller. Along the same lines, it should also be noted that if the aim was to map the seven land cover classes (not just the Hakea sericea class), the most suitable feature space for WV2 would be "Texture 1" (KHAT: 0.7846; OA: $82.20 \%$ ), which is similar to the results obtained by Fernandez-Luque et al. [42]. Mapping all the cover classes has been proven to be interesting when monitoring Hakea sericea, since fragmented landscapes, with a multitude of anthropogenic and ecological disturbances are more prone to alien plant invasion [11]. Thus, the land cover maps can be used to estimate the degree of fragmentation, which would be then input into the risk model for the spread of the bush.

It should be highlighted that, for the UAV imagery, although using the texture ("Texture 1") led to a smaller omission error (PA: $80.77 \%$ ), this data set was not selected because it was significantly less accurate for the rest of the criteria and the spatial representation of the classification was not suitable. Large areas of Hakea sericea were misclassified as woodlands, which did not happen when the textures were not used. The next criterion (commission error) was applied and therefore "Basic 1" was chosen as the optimal dataset, since (i) there were no differences between this data set and the ones which included the indices and (ii) "Basic 1" required the least amount of time to be created and processed. In a similar work, Fernandez-Luque et al. [41] mapped impervious areas using archival orthophotographs and found that the classifications were improved by using textural features. However, their work did not involve mapping vegetation land covers. Jones et al. [27] also found that the use of textures increased the accuracy for mapping Japanese knotweed from aerial images, but they did not provide an assessment of accuracy so their results are difficult to compare. Franklin et al. [65] succeeded in detecting knotweed using a classifier based on pixels combined with textural information derived from a moving kernel. The low impact of the use of the texture in our work might be related to the size of the window used to calculate it, which maybe was not optimal for the image. The influence of the window size has been recognized by several authors $[44,66,67]$, but so far there is no general method to determine the optimum size.

The approach and the results obtained in this paper are not meant to be used for the early detection of a small, nascent population of Hakea sericea. The areas tested and the maps obtained correspond with heavily infested locations. This information is not just useful to map the invasion and plan its mitigation $[1,8,10]$, but it is also a valuable tool for risk assessment by growing the knowledge about temporal and spatial patterns of the invasion [12]. At a regional scale, the risk of invasion could be also evaluated by mapping burnt areas, which are more likely to be infested by Hakea sericea [2,12], using remote sensing. WV2 or Sentinel 2B imagery could be used for that purpose [68-70].

We propose the use of the tools tested in this paper in the frame of a management plan to control the invasion of Hakea sericea in the North of Portugal, focusing on the largest and most infested areas. That plan should, at least, include the following steps (in chronological order):

(i) identify the areas where invasive Hakea sericea is already installed;

(ii) develop a working protocol in a procedural framework for quick and easy monitoring of the species;

(iii) identify the key areas that need to be controlled for intervention and eradication of the species;

(iv) after controlling the species, promote the recovery or installation of mixed forests in the area, when possible;

(v) maintain and manage the new forest.

\section{Conclusions}

The results show that both UAV and WV2 imagery are suitable for mapping the invasive species Hakea sericea. WV2 had user's and producer's accuracies greater than 93\% (KHAT: 0.95), 
while the classifications with the UAV orthophotographs obtained accuracies higher than $75 \%$ (KHAT: 0.51). The acquisition date might have been crucial in order to achieve these high accuracies using WV2, and therefore it is recommended that the data used corresponds with the flowering period (December-February). Both sources of imagery can be used together to access different spatio-temporal scales of observation, which is very useful from an operational point of view since the detection and control phases have different spatial and temporal requirements.

The most suitable data to use as input consisted of all the multispectral bands that were available for each image. For WV2, the use of indices made the accuracies decrease, while for the classification of the UAV orthoimages, their use did not modify the results significantly.

Regarding the use of textural features (variance), it did not increase the accuracies for the Hakea sericea class $(p<0.05)$ for either the WV2 or the UAV imagery. However, for the general classification (all the land cover classes) using WV2, the use of textures increased the accuracy, and its use is therefore recommended since the land cover maps can be used to estimate the degree of fragmentation in the landscape, which is highly related to the risk of invasion.

Acknowledgments: The authors would like to thank the three anonymous reviewers who helped improve the manuscript with their comments and suggestions.

Author Contributions: F.A. and C.P. conceived and designed the experiments; F.A. and J.J. performed the experiments; F.A., C.P. and J.J. analyzed the data; C.P. contributed materials/analysis tools; F.A., C.P. and J.J. wrote the paper.

Conflicts of Interest: The authors declare no conflict of interest.

\section{References}

1. Morais, M.; Marchante, E.; Marchante, H. Big troubles are already here: Risk assessment protocol shows high risk of many alien plants present in Portugal. J. Nat. Conserv. 2017, 35, 1-12. [CrossRef]

2. Richardson, D.M.; Van Wilgen, B.; Mitchell, D.T. Aspects of the reproductive ecology of four Australian Hakea species (Proteaceae) in South Africa. Oecologia 1987, 71, 1432-1939. [CrossRef] [PubMed]

3. European Commission. Executive Summary of the Impact Assessment on the Prevention and Management of the Introduction and Spread of Invasive Species; European Commission: Brussels, Belgium, 2013.

4. Almeida, J.D.; Freitas, H. Exotic naturalized flora of Continental Portugal-A new assessment. Bocconea 2012, 24, 231-237.

5. Marchante, H.; Marchante, E.; Freitas, H. Invasive plant species in Portugal: An overview. In Proceedings of the International Workshop on Invasive Plants in Mediterranean Type Regions of the World, Mèze, France, 25-27 May 2005; Council of Europe Publishing: Strasbourg, France, 2007; pp. 99-103.

6. Ministério do Ambiente. Decreto-Lei n (565/99 de 21 de Dezembro. In Diário da República-I Série-A; Ministério do Ambiente: Lisbon, Portugal, 1999; Volume 295, pp. 9100-9114.

7. Marchante, H.; Morais, M.; Freitas, H.; Marchante, E. Guia Prático Para a Identificacão de Plantas Invasoras em Portugal; Imprensa daUniversidade de Coimbra: Coimbra, Portugal, 2014.

8. Esler, K.J.; van Wilgen, B.W.; Roller, K.S.T.; Wood, A.R.; van der Merwe, J.H. A landscape-scale assessment of the long-term integrated control of an invasive shrub in South Africa. Biol. Invasions 2010, 12, 211-218. [CrossRef]

9. Forsyth, G.G.; Le Maitre, D.C.; O'Farrell, P.J.; Van Wilgen, B.W. The prioritisation of invasive alien plant control projects using a multi-criteria decision model informed by stakeholder input and spatial data. J. Environ. Manag. 2012, 103, 51-57. [CrossRef] [PubMed]

10. Roura-Pascual, N.; Richardson, D.M.; Krug, R.M.; Brown, A.; Chapman, R.A.; Forsyth, G.G.; Le Maitre, D.C.; Robertson, M.P.; Stafford, L.; Van Wilgen, B.W.; et al. Ecology and management of alien plant invasions in South African fynbos: Accommodating key complexities in objective decision making. Biol. Conserv. 2009, 1595-1604. [CrossRef]

11. Baard, J.A.; Kraaij, T. Alien flora of the Garden Route National Park, South Africa. J. Bot. 2014, 94, 51-63. [CrossRef]

12. Bradley, B.A. Remote Detection of Invasive Plants: A Review of Spectral, Textural and Phenological Approaches. Biol. Invasions 2014, 16, 1411-1425. [CrossRef] 
13. Van Wilgen, B.W.; Richardson, D.M. The effects of alien shrub invasions on vegetation structure and fire behaviour in South African fynbos shrublands: A simulation study. J. Appl. Ecol. 1985, 22, 955-966. [CrossRef]

14. Sousa, M.F.; Façanha, A.R.; Tavares, R.M.; Lino-Neto, T.; Gerós, H. Phosphate transport by proteoid roots of Hakea sericea. Plant Sci. 2007, 173, 550-558. [CrossRef]

15. Mateus, P.; Fernandes, P.M. Forest Fires in Portugal: Dynamics, Causes and Policies. In Forest Context and Policies in Portugal; Reboredo, F., Ed.; Springer: Berlin, Germany, 2014; Volume 19, pp. 97-115.

16. Fernandes, P.M.; Luz, A.; Loureiro, C. Changes in wildfire severity from maritime pine woodland to contiguous forest types in the mountains of northwestern Portugal. For. Ecol. Manag. 2010, 260, 883-892. [CrossRef]

17. Rego, F.C.; Silva, J.S. Wildfires and landscape dynamics in Portugal: A regional assessment and global implications. In Forest Landscapes and Global Change; Azevedo, J.C., Perera, A.H., Pinto, M.A., Eds.; Springer: New York, NY, USA, 2014; pp. 51-73.

18. Hulme, P.E. Biological Invasions: Winning the Science Battles but Losing the Conservation War? Oryx 2003, 37, 178-193. [CrossRef]

19. Huang, C.; Asner, G.P. Applications of Remote Sensing to Alien Invasive Plant Studies. Sensors 2009, 9, 4869-4889. [CrossRef] [PubMed]

20. Große-Stoltenberg, A.; Hellmann, C.; Werner, C.; Oldeland, J.; Thiele, J. Evaluation of Continuous VNIR-SWIR Spectra versus Narrowband Hyperspectral Indices to Discriminate the Invasive Acacia longifolia within a Mediterranean Dune Ecosystem. Remote Sens. 2016, 8, 334. [CrossRef]

21. Wallace, C.S.A.; Walker, J.J.; Skirvin, S.M.; Patrick-Birdwell, C.; Weltzin, J.F.; Raichle, H. Mapping Presence and Predicting Phenological Status of Invasive Buffelgrass in Southern Arizona Using MODIS, Climate and Citizen Science Observation Data. Remote Sens. 2016, 8, 524. [CrossRef]

22. West, A.M.; Evangelista, P.H.; Jarnevich, C.S.; Kumar, S.; Swallow, A.; Luizza, M.W.; Chignell, S.M. Using multi-date satellite imagery to monitor invasive grass species distribution in post-wildfire landscapes: An iterative, adaptable approach that employs open-source data and software. Int. J. Appl. Earth Obs. Geoinf. 2017, 59, 135-146. [CrossRef]

23. Liu, M.; Li, M.; Li, L.; Man, W.; Jia, M.; Wang, Z.; Lu, C. Monitoring the Invasion of Spartina alterniflora Using Multi-source High-resolution Imagery in the Zhangjiang Estuary, China. Remote Sens. 2017, 9, 539. [CrossRef]

24. Ng, W.T.; Rima, P.; Einzmann, K.; Immitzer, M.; Atzberger, C.; Eckert, S. Assessing the Potential of Sentinel-2 and Pléiades Data for the Detection of Prosopis and Vachellia spp. in Kenya. Remote Sens. 2017, 9. [CrossRef]

25. Bustamante, J.; Aragonés, D.; Afán, I.; Luque, C.J.; Pérez-Vázquez, A.; Castellanos, E.M.; Díaz-Delgado, R. Hyperspectral Sensors as a Management Tool to Prevent the Invasion of the Exotic Cordgrass Spartina densiflora in the Doñana Wetlands. Remote Sens. 2016, 8, 1001. [CrossRef]

26. Chance, C.M. Mapping the Distributions of Two Invasive Plant Species in Urban Areas with Advanced Remote Sensing Data. Ph.D. Thesis, University of British Columbia, Vancouver, BC, Canada, 2016. Available online: https://open.library.ubc.ca/cIRcle/collections/24/items/1.0305687 (accessed on 5 August 2016).

27. Jones, D.; Pike, S.; Thomas, M.; Murphy, D. Object-Based Image Analysis for Detection of Japanese Knotweed s.l. taxa (Polygonaceae) in Wales (UK). Remote Sens. 2011, 3, 319-342. [CrossRef]

28. Aragonés, D.; Fernández-Zamudio, R.; Bustamante, J.; García-Murillo, P.; Díaz-Delgado, R.; Cirujano, S. Cartografía de la superficie invadida por Azolla filiculolides en el parque nacional de Doñana mediante imágenes Landsat. In Proceedings of the XIII Conference of the Spanish Association of Remote Sensing, Calatayud, Spain, 23-26 September 2009; pp. 97-100.

29. Ounuan, M.A. Utilização das Imagens de Satélite na Classificação e Distribuição de Invasoras Lenhosas. Master's Thesis, Escola Superior Agrária de Ponte de Lima do Instituto Politécnico de Viana do Castelo, Ponte de Lima, Portugal, 2008.

30. Müllerová, J.; Brůna, J.; Bartaloš, T.; Dvořák, P.; Vítková, M.; Pyšek, P. Timing Is Important: Unmanned Aircraft vs. Satellite Imagery in Plant Invasion Monitoring. Front. Plant Sci. 2017, 8, 887. [CrossRef] [PubMed]

31. Boelman, N.T.; Asner, G.P.; Hart, P.J.; Martin, R.E. Multi-trophic invasion resistance in Hawaii: Bioacoustics, field surveys, and airborne remote sensing. Ecol. Appl. 2007, 17, 2137-2144. [CrossRef] [PubMed] 
32. Zuo, P.; Zhao, S.H.; Liu, C.A.; Wang, C.H.; Liang, Y.B. Distribution of Spartina spp. along China's coast. Ecol. Eng. 2012, 40, 160-166. [CrossRef]

33. Huang, H.M.; Zhang, L.Q. A study of the population dynamics of Spartina alterniflora at Jiuduansha shoals, Shanghai, China. Ecol. Eng. 2007, 29, 164-172. [CrossRef]

34. Wang, A.Q.; Chen, J.D.; Jing, C.W.; Ye, G.Q.; Wu, J.P.; Huang, Z.X.; Zhou, C.S. Monitoring the Invasion of Spartina alterniflora from 1993 to 2014 with Landsat TM and SPOT 6 Satellite Data in Yueqing Bay, China. PLoS ONE 2015, 10, e0135538. [CrossRef] [PubMed]

35. Groeneveld, D.P.; Watson, R.P. Near-infrared discrimination of leafless saltcedar in wintertime Landsat TM. Int. J. Remote Sens. 2008, 29, 3577-3588. [CrossRef]

36. Cirujano, S.; García-Murillo, P.; Fernandez-Zamudio, R.; Espinar, J.M.; Rubio, A.; Meco, A.; Lopéz-Bravo, I.; Sanchez-Andrés, R.; Sanchez-Carrillo, S.; Moreno, M.; et al. Estudio Y Control del Helecho Acuático Invasor Azolla Filiculoides en los Humedales del Parque Nacional de Doñana 2005-2008; Technical Report; Royal Botanic Garden of Madrid (CSIC): Madrid, Spain, 2008.

37. Fuller, D.O. Remote detection of invasive Melaleuca trees (Melaleuca quinquenervia) in South Florida with multispectral IKONOS imagery. Int. J. Remote Sens. 2005, 26, 1057-1063. [CrossRef]

38. Van Der Sande, C.J.; De Jong, S.M.; De Roo, A.P.J. A segmentation and classification approach of IKONOS-2 imagery for land cover mapping to assist flood risk and flood damage assessment. Int. J. Appl. Earth Obs. Geoinf. 2003, 4, 217-229. [CrossRef]

39. Perea, A.J.; Meroño, J.E.; Aguilera, M.J. Clasificación orientada a objetos en fotografías aéreas digitales para la discriminación de usos del suelo. Interciencia 2009, 34, 612-616.

40. Blaschke, T. Object based image analysis for remote sensing. ISPRS J. Photogramm. Remote Sens. 2010, 65, 2-16. [CrossRef]

41. Fernandez-Luque, I.; Aguilar, F.J.; Álvarez, M.F.; Aguilar, M.A. Non-Parametric Object-Based Approaches to Carry Out ISA Classification From Archival Aerial Orthoimages. IEEE J. Sel. Top. Appl. Earth Obs. Remote Sens. 2013, 6, 2058-2071. [CrossRef]

42. Fernandez-Luque, I.; Aguilar, F.J.; Aguilar, M.A.; Álvarez, M.F. Extraction of impervious surface areas from GeoEye-1 and WorldView-2 VHR satellite imagery using an object-based approach. J. Sel. Top. Appl. Earth Obs. Remote Sens. 2014, 7, 4681-4691. [CrossRef]

43. Shamsoddini, A.; Trinder, J.C.; Turner, R. Pine plantation structure mapping using WorldView-2 multispectral image. Int. J. Remote Sens. 2013, 34, 3986-4007. [CrossRef]

44. Tsai, F.; Chou, M.-J. Texture augmented analysis of high resolution satellite imagery in detecting invasive plant species. J. Chin. Inst. Eng. 2006, 29, 581-592. [CrossRef]

45. Updike, T.; Comp, C. Radiometric Use of WorldView-2 Imagery. Technical Note. Available online: https:/ / dg-cms-uploads-production.s3.amazonaws.com/uploads/document/file/104/Radiometric_ Use_of_WorldView-2_Imagery.pdf (accessed on 17 July 2017).

46. Laben, C.A.; Brower, B.V. Process for Enhancing the Spatial Resolution of Multispectral Imagery Using Pan-Sharpening. US Patent 6,011,875, 4 January 2000.

47. Jensen, J.R. Introductory to Digital Image Processing: A Remote Sensing Perspective, 3rd ed.; Prentice Hall: Upper Saddle River, NJ, USA, 2005.

48. Benz, U.C.; Hofmann, P.; Willhauck, G.; Lingenfelder, I.; Heynen, M. Multi-resolution, object-oriented fuzzy analysis of remote sensing data for GIS-ready information. ISPRS J. Photogramm. Remote Sens. 2004, 58, 239-258. [CrossRef]

49. Definiens Imaging. eCognition 8.9 Reference Book; eCognition Document Version 1.2.1; Definiens Imaging: Munich, Germany, 2010.

50. Keller, J.M.; Gray, M.R.; Givens, J.A. Fuzzy k-nearest neighbor algorithm. IEEE Trans. Syst. Man Cybern. 1985, SMC-15, 580-585. [CrossRef]

51. Duda, R.O.; Hart, P.E. Pattern Classification and Scene Analysis; Wiley and Sons: New York, NY, USA, 1973.

52. Mallinis, G.; Koutsias, N.; Tsakiri-Strati, M.; Karteris, M. Object-based classification using Quickbird imagery for delineating forest vegetation polygons in a Mediterranean test site. ISPRS J. Photogramm. Remote Sens. 2008, 63, 237-250. [CrossRef]

53. Baatz, M.; Hoffmann, C.; Willhauck, G. Progressing from object-based to object-oriented image analysis. In Object Based Image Analysis; Blaschke, T., Lang, S., Hay, G.J., Eds.; Springer: New York, NY, USA, 2008; pp. 29-42. 
54. Congalton, R.G.; Green, K. Assessing the Accuracy of Remotely Sensed Data, 2nd ed.; CRC Press: Boca Raton, FL, USA, 2009.

55. Sauro, J.; Lewis, J.R. Estimating completion rates from small samples using binomial confidence intervals: Comparison and recommendations. Proc. Human Factor Ergon. Soc. 2005, 49, 2100-2104. [CrossRef]

56. Congalton, R.G. A review of assessing the accuracy of classifications of remotely sensed data. Remote Sens. Environ. 1991, 37, 35-46. [CrossRef]

57. Jones, H.G.; Vaughan, R.A. Remote Sensing of Vegetation: Principles, Techniques, and Applications; Oxford University Press: Oxford, UK, 2010.

58. Sanchez-Flores, E.; Rodriguez-Gallegos, H.; Yool, S.R. Plant invasions in dynamic desert landscapes. A field and remote sensing assessment of predictive and change modeling. J. Arid Environ. 2008, 72, 189-206. [CrossRef]

59. Laba, M.; Downs, R.; Smith, S.; Welsh, S.; Neider, C.; White, S.; Richmond, M.; Philpot, W.; Baveye, P. Mapping invasive wetland plants in the Hudson River National Estuarine Research Reserve using QuickBird satellite imagery. Remote Sens. Environ. 2008, 112, 286-300. [CrossRef]

60. Everitt, J.H.; Anderson, G.L.; Escobar, D.E.; Davis, M.R.; Spencer, N.R.; Andrascik, R.J. Use of remote sensing for detecting and mapping leafy spurge (Euphorbia esula). Weed Technol. 1995, 9, 599-609.

61. Everitt, J.H.; Escobar, D.E.; Alaniz, M.A.; Davis, M.R.; Richerson, J.V. Using spatial information technologies to map Chinese tamarisk (Tamarix chinensis) infestations. Weed Sci. 1996, 44, 194-201.

62. Müllerová, J.; Pyšek, P.; Jarošík, V.; Pergl, J. Aerial photographs as a tool for assessing the regional dynamics of the invasive plant species Heracleum mantegazzianum. J. Appl. Ecol. 2005, 42, 1042-1053. [CrossRef]

63. Somodi, I.; Čarni, A.; Ribeiro, D.; Podobnikar, T. Recognition of the invasive species Robinia pseudacacia from combined remote sensing and GIS sources. Biol. Conserv. 2012, 150, 59-67. [CrossRef]

64. Müllerová, J.; Pergl, J.; Pyšek, P. Remote sensing as a tool for monitoring plant invasions: Testing the effects of data resolution and image classification approach on the detection of a model plant species Heracleum mantegazzianum (giant hogweed). Int. J. Appl. Earth Obs. Geoinf. 2013, 25, 55-65. [CrossRef]

65. Dorigo, W.; Lucieer, A.; Podobnikar, T.; Čarni, A. Mapping invasive Fallopia japonica by combined spectral, spatial, and temporal analysis of digital orthophotos. Int. J. Appl. Earth Obs. Geoinf. 2012, 19, 185-195. [CrossRef]

66. Franklin, S.E.; Hall, R.J.; Moskal, L.M.; Maudie, A.J.; Lavigne, M.B. Incorporating texture into classification of forest species composition from airborne multispectral images. Int. J. Remote Sens. 2000, 21, 61-79. [CrossRef]

67. Marceau, D.J.; Howarth, P.J.; Dubois, J.-M.M.; Gratton, D.J. Evaluation of the grey-level co-occurrence matrix method for land-cover classification using SPOT imagery. IEEE Trans. Geosci. Remote Sens. 1990, 28, 513-519. [CrossRef]

68. Verhegghen, A.; Eva, H.; Ceccherini, G.; Achard, F.; Gond, V.; Gourlet-Fleury, S.; Cerutti, O.P. The Potential of Sentinel Satellites for Burnt Area Mapping and Monitoring in the Congo Basin Forests. Remote Sens. 2016, 8, 986. [CrossRef]

69. Mallinis, G.; Mitsopoulos, I.; Chrysafi, I. Evaluating and comparing Sentinel 2A and Landsat-8 Operational Land Imager (OLI) spectral indices for estimating fire severity in a Mediterranean pine ecosystem of Greece. GISci. Remote Sens. 2017, 1-18. [CrossRef]

70. Wu, Z.; Middleton, B.R.; Hetzler, R.; Vogel, J.M.; Dye, D.G. Vegetation burn severity mapping using Landsat-8 and WorldView-2. Photogramm. Eng. Remote Sens. 2015, 2, 143-154. [CrossRef]

(C) 2017 by the authors. Licensee MDPI, Basel, Switzerland. This article is an open access article distributed under the terms and conditions of the Creative Commons Attribution (CC BY) license (http://creativecommons.org/licenses/by/4.0/). 